\title{
Favour and Power in the Acquaintance Society: Interpreting a Conflict in White Deer Plain
}

\author{
Meng Yuzhong \\ Ministry of Public Foundation, Zhejiang Police School, Hangzhou, China
}

Email address:

mengyuzhong@zijicxy.cn

To cite this article:

Meng Yuzhong. Favour and Power in the Acquaintance Society: Interpreting a Conflict in White Deer Plain. International Journal of Law and Society. Vol. 4, No. 1, 2021, pp. 23-27. doi: 10.11648/j.ijls.20210401.13

Received: December 28, 2020; Accepted: January 11, 2021; Published: January 28, 2021

\begin{abstract}
The White Deer Plain constructs an ideal acquaintance society. The conflict over Widow Li's 0.24 hectares of irrigated land between Bai Jiaxuan and Lu Zilin is a typical case in such society. Combining Chinese local historical facts with the text of White Deer Plain, the sociological method is used to analyze this dispute, and the following conclusions can be drawn: First, "Face"is still highly valued in rural China; Second, As the villagers are closely bonded in agricultural life, neither the participants nor the on-lookers want to destroy the harmonious relations; Third, When there is a dispute, villagers tend to mediate through a third party, because it relatively doesn't destroy the existing harmonious relationship. The key to third party mediation is to find an authoritative mediator who is good at observing the thoughts of both parties in a dispute. In this novel, the conflict between Bai Jiaxuan and Lu Zilin is solved smoothly, because Mr. Zhu's prestige, as well as Mr. Zhu's personal letters meet the psychological demands of Bai Jiaxuan and Lu Zilin. After Bai Jiaxuan and Lu Zilin apologized to each other and agreed to waive the debt of Widow Li, peace returned to the Plain. But new interpersonal "debts" and "returns" with no fixed term emerge. The significance of this conclusion is that it can be used as a reference to solve the conflict in China's rural areas.
\end{abstract}

Keywords: White Deer Plain, Conflicts, Acquaintance Society, Meditation, Rural Conflicts

\section{Introduction}

The first few pages of the White Deer Plain give a complete record of the ins and outs of a dispute. The widow of the $\mathrm{Li}$ family first pledged a six-fen $\left(1 \mathrm{fen}=66.666 \mathrm{~m}^{2}\right)$ irrigated land to the Lu family, and then sold it to the Bai family. When Bai Jiaxuan surveys the land with the title deed in his hand, he sees $\mathrm{Lu}$ Zilin commanding a hired hand to prepare a plough and enclose the land. They squabble at once and come to blows immediately:

Two men grapple with each other from the widow's farmland to a dry ditch on the edge of the field, and fall into a haystack in the ditch, then they get up and continue to tussle. Next, they again are dragged to the farmland that was just tilled. At this time, many men and women come from the village. At first Lu Zilin's nephews join the fight, then Bai Jiaxuan's male close relatives also start to fight, soon it becomes a brawl between Bai and $\mathrm{Lu}$ families, leaving ripped pieces of clothes and lost cloth shoes all over the ground. [1]

Finally, the dispute, where both sides are so indignant that they want to file a complaint to the county government, is quickly quelled with a manner of mediation unique to rural China. The entire process seems simple, but actually reflects human relationship, power and even folk customs in the White Deer Plain. It is also infiltrated by the author's understanding of and experience in rural life. Thus, comprehensively analysing the actual situation of folks and the text of the White Deer Plain is noteworthy. In recent years, there emerge several articles, these articles use the text of White Deer Plain to carry on the sociology research which have obtained remarkable achievement. It is a pity that these articles haven't focus on this disput [2].

\section{Cause of Dispute: Face}

Ming Enpu, an American missionary in modern times, pointed out the importance of face in the lives of the Chinese people after he living in China for many years. He believed that 'Once understood correctly, face is a key that can open the lock of many important qualities of Chinese' [3]. Lu Xun, who was familiar with the Chinese national character, strongly agreed with this, 'they (foreigners) think of this thing as 
elusive, yet it is the creed of the Chinese spirit, grasping this is like pulling the pigtail twenty-four years ago, the whole body will follow' [4]. The contemporary Lin Yutang also echoed, 'It (face) is the most subtle point of Chinese social mentality. It is abstract, intangible, yet is the most delicate standard for the Chinese people to adjust social communications' [5].

What are specific the connotations of the abstract intangible face? The definition offered by social psychology may be more targeted: 'face refers to social status or reputation obtained by everyone by achieving something in society. This social status or reputation consists of family background attributes such as gender, family background and ancestral home; individual qualities like learning, looks and ability; and personal efforts including wealth, authority and social relations' [6]. Consequently, in the network of public relations, face virtually represents the level of social status and reputation: the greater the face, the more the disposable resources you have and the greater the power you have in the mind of the public. Frequently, to achieve face (which implies power), people will at least ostensibly give face to one another, which means making a show intentionally to leave a particular impression on others. As for the type of image that one hopes to impress on the mind of others, it 'depends on his personal values and his judgment of the values of others in his network of contacts' [6].

Chen Zhongshi, who is 'a firm follower of realistic writing' [7], built an ideal acquaintance society in the White Deer Plain. People were born, raised and died in this place. On the plain, 'every kid grows up under the eyes of others, and these kids are accustomed to people around them since childhood' [8]. Bai Jiaxuan is familiar with Lu Zilin when Lu wore a silver plate, a silver lock and a small silver bell as a child, whereas Bai Ling remembers the thrill when Lu Zhaopeng played on a swing on the Plain after returning from school. In the White Deer Plain where strangers do not exist, the face and implications that it represents are particularly important.

In this dispute, Li's widow initially sold her land to Lu Zilin and borrowed five-dou ( 1 dou=1 decalitre) of wheat and eight silver dollars and signed her name on the contract and settled. Later, after hearing that Bai Jiaxuan gives a higher offer to a gambler's son, she wants to sell it to Bai and use the money given by Bai to repay Lu Zilin. As for Lu Zilin, he says to his father, 'I don't care about the six-fen land of Li's widow. Bai is passing over my head!' Lu Taiheng agreed. Pass over one's head is a dialect in the central Shanxi plain and indicates that a standing person passes over the head of a squatter sideways with one leg and implies bullying and humiliation [9]. Bai unknowingly bought the irrigated land of Li's widow, such that saying that Bai intentionally humiliates $\mathrm{Lu} \mathrm{Zilin} \mathrm{is}$ groundless. Moreover, Lu Zilin takes this scenario as a pretext as $\mathrm{Lu}$ Taiheng points out the underlying cause: before Bai is full-fledged, allowing Bai to lose face is necessary to challenge his power and to show the attitude: 'my son at least can become a rival to Bai, we won't let them pass over our head!' (Chapter 4), thus making Lu Zilin able to stand up to him as an equal in the White Deer Plain.

In a similar manner, Bai Jiaxuan does not care about this farmland. He minds that $\mathrm{Lu}$ encloses the land without informing him in advance, which constitutes brazenly letting him lose face and means provocation and humiliation. Therefore, he needs to energetically maintain his face and power. He says to the people in his family who mollify him, 'since Li's widow is shortsighted. I will by no means want her land if you say anything to me! You enclosed the land with horses and ploughs without saying anything, this was nothing less than peeing over my face!' (Chapter 4). Bai grows firm about his determination regardless of matter how shortsighted the widow is because this shortsightedness has nothing to do with him. He now has the title deed in his hands, so he has grounds for a lawsuit in the state or county.

Consequently, the crux of this dispute is face. In essence, the dispute over face is the contention of the parties for a say in the White Deer Village, where the Bai and $\mathrm{Lu}$ families stand on equal footing. Although the Bai family is the head, the $\mathrm{Lu}$ family enjoys a high status, as evidenced by the power confrontation between them throughout the book. The dispute caused by the six-fen irrigated land of the widow occurs in the first few pages of the book, when power shifts between the two generations, namely, Bai Bingde+Lu Taiheng and Bai Jiaxuan+Lu Zilin. At this time, Bai Jiaxuan and Lu Zilin just enter the arena of social intercourse, and both are eager to build their reputation. For this reason, they consider the face and implications behind the face extremely important. Moreover, the entire book undergoes ups and downs amid decades of confrontations of 'lose face/reduce power' and 'gain face/increase power' between the two families (For example, in Chapter 18 of the White Deer Plain, Bai Xiaowu sells a property to Lu Zilin, where the Bai family loses face, whereas the Lu family boosts their power. In Chapter 31, Bai Xiaowen buys back the property, which leads the Lu family to lose face, whereas the Bai family increases their power).

\section{Survival Philosophy: Future-orientation of Harmonious Coexistence}

For a long time, the pursuit of harmony is considered a prominent characteristic of the Chinese culture, which is closely linked to the ecological fragility of the traditional agricultural society. On the one hand, various forms of natural and social disasters require the society to unite and help one another, such as making concerted efforts to combat floods, organising a corps protection team and building fortifications to resist thieves and brigands. On the other hand, the risks are unpredictable. As individual ability to resist risks is limited, everyone anticipates that they themselves will seek help from others [10]. Therefore, in a rural society with extremely low mobility, people aim for a smooth and orderly future and are willing to and need to build rapport with others. After extensive field investigations, scholars point out that in a rural acquaintance society, villagers are more concerned with the state of life after a dispute. Therefore, the most ideal way of settling the dispute is settling it without destroying the 
previous harmony for the benefit of future intercourse [11].

In the White Deer Village, several matters require the Bai and Lu families to 'join hands to handle' (said Lu Taiheng), such as overhauling an ancestral temple and running an old-style private school. Particularly notable is that Bai Jiaxuan and Lu Zilin make concerted efforts to organise villagers to resist bloodthirsty white wolves. In accordance with the tradition of revamping an ancestral temple, Bai Jiaxuan is responsible for collecting food, whereas Lu Zilin is in charge of commanding over the revamp of enclosures. They then divide men aged over 16 into groups for nightly patrols. The solid buildings and tight defences work soon that after a while, a white light (white wolf) is thrown out of the wall by the gun of the villagers.

Conversely, if the Bai and Lu families are no longer on good terms, then the whole village will be affected. For example, after the death of Tian Xiao'e, a plague hangs over the White Deer Village. Lu Zilin then takes Zhaopeng's advice, asking his hired hand Liu Mou'er to haul back a big pile of quicklime and to spread the lime powder over every corner of his yard. Although Bai Jiaxuan accepts Mr. Leng's suggestion, he hangs wormwood and inserts peach branches. The villagers comply with the practice of the Bai family. However, people continue to die, including Xiancao. If Bai Jiaxuan calmly held a discussion with Lu Zilin over how to control the plague and carefully analysed which method is more effective, then the tragedy of the White Deer Village could have been avoided.

For the villagers, they have lived in this place for generations and anticipate a stable and peaceful life in the future. As such, keeping a close or even a superficial close relationship is extremely necessary for the Bai and Lu families. As Mr. Leng said, 'the White Deer Village cannot last without Jiaxuan as well as Zilin' (Chapter 8). The same is true of Bai Jiaxuan and Lu Zilin because they will live together in the White Deer Village for the rest of their lives and consider the future. Therefore, any grudge should be 'deeply hidden by them on their own initiative', because 'they both need to keep it that way' (Chapter 8). Apart from the Bai and Lu families, this notion is true for other individuals. For instance, $\mathrm{Lu}$ Zhaohai once threatened Yue Weishan, the head of Zishui County, with his military might. Lu Zilin triumphantly returns to the plain under the wing of his son, but Tian Fuxian wakes him up: 'Why bother? He just lives on army provisions, can he station himself here for a lifetime?' (Chapter 26). This view makes Lu Zilin ashamed of his shortsightedness.

Similar situations continue to happen in China today. In a village in southern Ningxia, a newly-open wood processing plant severely disturbs and pollutes the environment of the residents nearby. However, several villagers aged over 60 years who were affected stated they will not protest: 'we live in the same village, why resist?' [12] In fact, these people abide by familiar rules passed down across generations in rural life, namely, the value orientation that aims at the future. Thus, the people exert their best efforts to maintain the existing harmony.

\section{Mediation Method: A Third Party Without Public Power}

Academic circles of the litigation hold that the methods for settling disputes are divided into three types, namely, self-help remedy, public remedy and social remedy. Self-help remedy refers to the parties involved in achieving the rights and interests and resolving disputes within their power. Public remedy denotes a state organ that wields public power to settle a dispute through legal procedures. Lastly, social relief pertains to a third party without public power that intervenes in the name of neutral stance to settle a dispute [13]. In a rural society, the ideal state is ending a dispute without affecting relationships between acquaintances. Then, when personal power is unable to reconcile, reconcilement by a third party without public power is the most ideal method for settling.

Settling a dispute by a third party without public power is a longstanding practice among the people. As early as the Tang Dynasty, persons were assigned to mediate and handle disputes in the market outside of government management: 'In the west market of Chang'an, there is a man surnamed Zhang who sells things and makes peace. His family is affluent and lives in Guangdeli' [14]. Scholars believe that this man had authority in the business district of the west market [14]. Although authority is the core factor that enables a third party without public power to reconcile, 'this kind of authority is the basis for disputing parties to trust someone and accept his persuasion, obey his decision on the disposition of conflicting rights and interests, and accept the disposition that he proposes' [11]. How, then, does a mediator acquire authority? In English, the word 'quan wei' denotes authority, whose root is similar to author. In general, in ancient Europe, author refers to individuals who can create new things and hence obtain people's trust. Afterwards, authority became a political concept that refers to a person with power who is obeyed by others and often has certain levels of credibility and capability [16]. The German sociologist Weber differentiated three types of authority, namely, Legal-rational, Traditional and Charismatic. Legal-rational authority is derived from the prestige given by laws and regulations; Traditional authority originates from public recognition gained in long-time social life; and Charismatic authority comes from personal charisma and unusual quality [17].

In the dispute in the White Deer Plain, Mr. Leng and Mr. Zhu act as a third-party mediator. For the first time, when the situation worsens, such that the Bai and Lu families exchange blows, Mr. Leng first arrives at the site and asks them to stop and brings the two men to his traditional Chinese medicine hall. After cleaning up the blood stains and applying medicine, he says, 'if you two let the matter drop, then you may go back to have breakfast; if you will not stop, have breakfast and then go to the county to file a lawsuit' (Chapter 4). This reconcilement fails because both men remain resentful and want the county government to decide whose side is right. Afterward, Mr. Zhu shows up and writes a letter 'To Jiaxuan and Zilin: bullying each other and fighting to a litigation cause destruction to both sides. A rich man should also value 
benevolence and righteousness, step back and all will have more room' (Chapter 4) to make them feel touched and drop the litigation.

Mr. Leng and Mr. Zhu have high authority on the White Deer Plain. From the perspective of the concepts proposed by Weber, their authority is a mixture of Traditional and Charismatic authority. First, both have obtained public recognition in social life. Mr. Leng is a famous doctor in the White Deer Town who will not reject any patient and is widely respected. Mr. Zhu is a teacher at White Deer Academy and enjoys moral prestige among the people. Second, both have unusual character and charisma. Mr. Leng is composed and sharp-eyed during diagnosis, whereas Mr. Zhu is a wise man and a prophet. Importantly, he is a sage who owns the ideal qualities of a traditional intellectual. In addition, Mr. Zhu has a wide circle of friends and used to relieve the distress caused by an army that reached the city gate of Xi'an because of his connections with the grand coordinator Fang and governor Zhang. He was praised by the people. Moreover, access to social circles among the upper class is also important for a mediator. During the 14 th century in a small village in Montaillou, France, the dominant Clegg family long acted as 'a mediator between villagers society and the overall society' because they 'have access to Earls Court, Bishops House and Inquisition' [18].

After careful analysis, although Mr. Leng and Mr. Zhu have authority, Mr. Zhu enjoys a higher status as the sage in the mind of villagers. Furthermore, differences are notable between them in terms of mediation: Mr. Leng's first mediation was not thorough because he only pointed out to both men to either reconcile or litigate. Alternatively, Mr. Zhu analysed the pros and cons in a fair and reasonable manner: both sides will suffer great losses as a consequence of litigation. However, a mutual concession will lead to a beautiful vision of a harmonious future. In addition, Bai Jiaxuan and $\mathrm{Lu}$ Zilin struggle over face and the power represented by face. The letter written by the sage $\mathrm{Mr}$. Zhu is a form of face and requires both sides to apologise to each other. In effect, Lu has reached the purpose of being on an equal footing with Bai. For Bai, Lu let him lose face before, then apologises sincerely, which becomes a given face. The intricate dispute is resolved, and they become friends again as before.

\section{After the Dispute: Debt and Return}

Academic circles of litigation argue that to settle a dispute, one should achieve multilayered effects: 'first, remove conflicts and contradictions between parties involved; second, customary or legal obligations are fulfilled, customary or legal rights and interests are realised; third, authority and dignity of rules are safeguarded, and the order is restored; fourth, disputing parties abandon and change their contempt and confrontation against social order and related laws, regulations and systems' [11]. In this sense, the dispute between the two families is settled in an appropriate manner. The Bai and Lu families stop opposing each other, and the problem about interests in the widow's six-fen irrigated land is resolved because both men give up simultaneously. The White Deer Village restores its harmonious order as Bai Jiaxuan and $\mathrm{Lu}$ Zilin agree on reconcilement from the bottom of their hearts and continue to join hands to serve the public utilities for the village.

In the acquaintance society, the consequence of this dispute involves debt and return because the Bai and Lu families gave up their interests in the widow's six-fen irrigated land at the same time. On the one hand, favours owed can maintain the solidarity of a close community: 'solidarity of a close community relies on the debts owed to community members. It is seen most clearly in our society that friends rush to pay the bill, which means they want others to owe them a debt, just like an investment. If one owes a debt to another, one must find an opportunity to return the favour with more, to make the other side owe him a debt. This cycle maintains interpersonal cooperation' [8]. On the other hand, owing a debt will give rise to a domination-subordination relationship between two persons. 'One side can dominate the other side in specific matters, scope and area' [10]. In other words, one who owes a debt to the other needs to return the favour to the other. For instance, family A asks for help from family B regarding a funeral. As such, family B may govern family A for help when having a funeral as well, such that family A's help can be considered a return to family $B$. In terms of the degree of return, this concept is influenced by 'an individual's position in his network of differential relationships, his expectation for how long this relationship will last, and the nature of obligation possibly caused by follow-up transaction in the future' [6]. Notably, in an acquaintance society, the return cycle is dependent on circumstances because people tend not to haggle over the present due to a high life expectancy.

In the White Deer Plain, debt owed and returned are evident in nearly all aspects of life. For example, the debt of Bai Jiaxuan's father-in-law Wu Changgui to the Bai family began with the grandfather of Bai Jiaxuan, who recruited $\mathrm{Wu}$ an ordinary person who sold medicinal materials, as a drugstore's clerk and promoted him to a drugstore manager, which soon made him one of the four richest families in Panlong Town. Wu Changgui's return starts to manifest during the generation of Bai Jiaxuan: he lets his daughter marry Bai Jiaxuan, hands over poppy seeds to Bai and teaches Bai how to plant and manage it, especially with regard to cooking and processing, thus making the Bai family prosper with a growing population. In the same manner, Bai Jiaxuan and Lu Zilin give up their interests in the six-fen irrigated land of the Li family's widow and give the widow food and silver dollars. For favour, this widow owes a debt to the two families at the same time. However, when and how to return the favour or if the return will span two to three generations similar to the case of $\mathrm{Mr}$. Wu Changgui are not included in the contents of the novel.

\section{Summary}

The title page of the White Deer Plain quotes Balzac: 'novel is considered as the secret history of a nation'. The author 
Chen Zhongshi has immersed himself in rural China for many years and gained a deep understanding of folk customs that pervade all aspects of life. He said, 'I have confidence in rural life not only because I grew up here', 'but also because I have worked here for ten years as an administrative cadre at the grass-roots level' [7]. These life experiences helped the author gain insights into ancient and modern China and build a highly representative White Deer Plain, which clearly demonstrates 'these ways of life, communication and speaking of people nearly a century ago' [7] and leaves a space sample for us to understand China of a hundred years ago.

This dispute in the White Deer Plain is enlightening for grassroots governance at present. In the case of a dispute in a village, the villagers' first thought would be to settle it behind closed doors, and the village cadre frequently acts as the mediator who ends such a dispute. For example, in a dispute over farmland in a place, the parties concerned believe that 'most of the time, the court cannot solve the problem. Let alone complicated procedures and lots of fees, even if you win the case, the decision will not necessarily be executed, although the law is fairer, yet it is not as fast as government (village cadre)' [19]. Next, for village cadres, the core principle of settling a dispute is quelling the litigation because retaining the stability and orderliness of the village life is an important achievement of their political career as a cadre. Moreover, at the national level, the mediation of a dispute by a third party "can avoid the losing of the reciprocal relationship between acquaintances because authority overemphasises law and the unstable order of village community brought by subsequent antagonism' [20]. In summary, being a third party without public power appears crucial to the role of the cadre as a mediator of disputes between villagers. The reason why the dispute between Bai Jiaxuan and Lu Zilin is quelled quickly is closely linked to the authority and wisdom of the meditators and subtle mentalities of the disputing parties, which provide examples and references for examining rural societies and addressing similar problems.

\section{References}

[1] Chen Zhongshi. White Deer Plain [M]. Beijing: Beijing October Literature and Art, 2011, P. 47. Note: the original texts quoted by this article are all from this White Deer Plain and will not be listed separately here.

[2] Yu yuhe. Family Rules and Village Governance --Taking White Deer Plain as an Example [J]. Jiangsu Social Sciences, 2019 (1): 12-18.

[3] Wang Liman. Image of Power: Spatial Poetic Interpretation of the Ancestral Hall in White Deer Plain [J]. Novel Comments, 2020 (1): 34-38.
[4] Ming Enpu. Characteristics of Chinese People [M]. Beijing: Jinghua Publishing House, 2002, P. 3.

[5] Lu Xun. On "Face" [M]. Complete Works of Lu Xun (6) [C]. Beijing: People's Literature Publishing House, 2005, P. 130.

[6] Lin Yutang. The Chinse People [M]. Beijing: Xuelin Publishing House, 1994, P. 203.

[7] Huang Guangguo \& Hu Xianjin. Favor and Face: Power Game of Chinese [M]. Beijing: China Renmin University Press, 2010, P. $21 ;$ P. 22; P. 31.

[8] Chen Zhongshi. Searching for Your Own Words [M]. Shanghai: Shanghai Literature and Art Publishing House, 2009, P. 43; P. 9; P. 31 .

[9] Fei Xiaotong. From the Soil - The Foundations of Chinese Society $[\mathrm{M}]$. Beijing: Jiangsu Literature and Art Publishing House, 2011, P. 9; P. 79.

[10] Han Jiawei. Metaphors, Rhetoric and Central Shaanxi Plain Culture of White Deer Plain [J]. Data of Culture and Education, 2016 (24): 12-13.

[11] Chen Baifeng. Rural Underworld: A Study of "Gangsters" in the Two-Lake Plain [M]. Beijing: China University of Political Science and Law Press, 2019, PP. 50-51; P. 52.

[12] Chen Baifeng. Violence and Humiliation: Dispute Settlement in Chen Village [J]. Law and Social Sciences, 2006 (6): 23-31.

[13] Ma Shutong. Strategy Choice for Rural Dispute Settlement and Justification in the Context of "Modern Acquaintance Society" [J]. Hubei Social Sciences, 2018 (2).

[14] Xiao Jianguo. Axiology of Civil Procedures [M]. Beijing: China Renmin University Press, 2000, PP. 34-36.

[15] Bai Xingjian. Three Dreams [M]. Shuofu Volume 4 [C]. Complete Library in the Four Branches of Literature of the Imperial Library.

[16] Cheng Qiang \& Dong Naibin. Spiritual Civilization of the Tang Dynasty: Folklore and Literature [M]. Beijing: China Social Sciences Press, 1996, P. 151.

[17] Wang Mingming \& Wang Sifu. Order, Justice and Authority of Rural Society [M]. Beijing: China University of Political Science and Law Press, 1997, P. 259.

[18] (German) Max Weber. Economy and Society (Volume 1) [M]. Beijing: The Commercial Press, 1997, PP 274-329.

[19] (French) Emmanuel Le Roy Ladurie. Montaillou [M]. Beijing: The Commercial Press, 2016, P. 111.

[20] Liu Gang \& Wang Fang. Public Power and Authority in the Mediation of Rural Disputes: An Investigation and Analysis of A Dispute over Farmland [J]. China Agricultural Observation, 2008 (11): 58-66.

[21] Zhao Xudong. Power and Justice: Dispute Settlement and Authority Diversity in Rural Society [M]. Tianjin: Tianjin Ancient Books Publishing House, 2003, PP. 271-272. 